\title{
Methylmercury induces caspase-dependent apoptosis and autophagy in human neural stem cells
}

\author{
Seung-Hee Chang1,,* Hong Jun Lee ${ }^{2, *}$, Bitna Kang ${ }^{1}$, Kyeong-Nam Yu', \\ Arash Minai-Tehrani ${ }^{1}$, Somin Lee ${ }^{1,3}$, Seung U. Kim ${ }^{2,4}$ and Myung-Haing Cho ${ }^{1,3,5,6}$ \\ ${ }^{1}$ Laboratory of Toxicology, College of Veterinary Medicine, Seoul National University, Seoul 151-742, Korea \\ ${ }^{2}$ Medical Research Institute, Chung-Ang University College of Medicine, Seoul 156-756, Korea \\ ${ }^{3}$ Graduate Group of Tumor Biology, Seoul National University, Seoul 110-799, Korea \\ ${ }^{4}$ Division of Neurology, Department of Medicine, University of British Columbia, Vancouver V6T 2B5, Canada \\ ${ }^{5}$ Graduate School of Convergence Science and Technology, Seoul National University, Seou151-742, Korea \\ ${ }^{6}$ Advanced Institute of Convergence Technology, Seoul National University, Suwon 443-270, Korea
}

(Received June 14, 2013; Accepted October 3, 2013)

\begin{abstract}
Methylmercury ( $\mathrm{MeHg}$ ) is a well-known human neurotoxic agent whose exposure sources are mainly environmental and aquatic-derived food. $\mathrm{MeHg}$ is reported to induce central nervous system disability. However, the exact mechanism of MeHg-induced neurotoxicity is still unknown. In this study, to investigate which cell death signaling pathway is related with MeHg-induced cytotoxicity, the effects of MeHg on apoptosis and autophagy were evaluated in HB1.F3 human neural stem cells (NSCs). Human NSCs were treated with $1 \mu \mathrm{M}$ of MeHg for $48 \mathrm{hr}$ and the effect of MeHg on cell signaling pathway was elucidated. MeHg inhibited Akt1/mTOR signaling that led to induction of caspase-dependent apoptosis and autophagy in the NSCs. Furthermore, retinoic acid (RA)-induced neuronal differentiation was inhibited by MeHg. Taken together, these results suggest that MeHg inhibits the differentiation of human NSCs by induction of caspase-dependent apoptosis and autophagy.
\end{abstract}

Key words: Methylmercury (MeHg), Human neural stem cell (NSC), Apoptosis, Autophagy

\section{INTRODUCTION}

Methylmercury $(\mathrm{MeHg})$ is a well-known human neurotoxic agent. The routes of exposure are mostly environmental and dietary sources through aquatic system. The central nervous system (CNS) is the most sensitive target organ for $\mathrm{MeHg}$, when exposures occur during the initial stages of brain development (Grandjean and Herz, 2011; Hassan et al., 2012). Therefore, $\mathrm{MeHg}$ is able to induce CNS disability (Clarkson et al., 2003) that leads to developmental deficits such as loss of intelligence quotient (IQ) points, reduction in language skills, impaired memory function and attention deficits in children exposed in-utero (Rice et al., 2003). In earlier studies, MeHg was found to induce apoptosis in cerebellar neurons at low concentration while at higher concentration $\mathrm{MeHg}$ induced necrosis in neurons (Castoldi et al., 2000; Daré et al., 2000). In apoptotic cell death, cell shrinkage, plasma membrane blebbing, activation of caspases, chromatin condensation and DNA fragmentation can be observed, whereas necrotic cell death can be characterized by cell and organelle swelling, loss of plasma membrane integrity and cell lysis (Orrenius et al., 2003). MeHg can also activate p38 mitogen-activated protein kinase (MAPK) and c-Jun $\mathrm{NH}_{2}-$ terminal kinase (JNK) signaling cascades belonging to the stress-activated protein kinase (SAPK) family (Kim and Sharma, 2004) and oxidative stress-mediated extracellular signal-regulated kinase (ERK)1/2 (Lu et al., 2011; Farina et al., 2011). However, the exact mechanism(s) of MeHginduced neurotoxicity still remains to be elucidated.

Apoptosis and autophagy are two closely related systems that induce cell death. Autophagy is a catabolic process involving the degradation of unmodified proteins and organelles through the lysosomal machinery. It is reported to be implicated in physiological cell death during development (Berry and Baehrecke, 2007). Autophagy is also

Correspondence: Myung-Haing Cho (E-mail: mchotox@snu.ac.kr)

Seung U. Kim (E-mail: sukim@mail.ubc.ca)

*These authors equally contributed to this work. 
positively regulated by phosphatase and tensin homolog (PTEN) and negatively regulated by oncogenic class I phosphoinositol-3-kinase (PI3K) signaling (Arico et al., 2001; Furuta et al., 2004). Autophagic cell death is morphologically characterized by an intact nucleus and the accumulation of cytoplasmic double-membrane autophagic vacuoles (Baehrecke, 2002; Reggiori and Klionsky, 2005). Autophagy-related gene (Atg) 6 (also known as beclin-1 and BECN1) is one of the essential components involved in autophagosome formation, and it displays increased expression during autophagy (Kondo et al., 2005; Maiuri et al., 2007). Microtubule-associated protein light chain 3 (LC3) is an autophagosome marker. Conversion of its cytosolic form, LC3-I, to its autophagic membrane form, LC3-II, is another key step in the induction of autophagy (Mizushima et al., 2002; Kuma et al., 2004). Therefore, an increase in the ratio of LC3-II to LC3-I coincides with autophagosome formation (Chang et al., 2012).

In the present study, we investigated the effects of $\mathrm{MeHg}$ on human neural stem cells (NSCs) by using F3 immortalized human NSC line. We focused on the mechanisms of MeHg-induced cell death in human NSCs, as well as on the effects of non-cytotoxic levels of $\mathrm{MeHg}$ on differentiation of human NSCs.

\section{MATERIALS AND METHODS}

\section{Chemical, reagents and antibodies}

Methylmercury (II) chloride (MeHg) and retinoic acid (RA) were purchased from Sigma-Aldrich (St. Louis, MO, USA), and caspase-3/7 inhibitor I from CalBiochem (La Jolla, CA, USA). Anti-actin, anti-BECN1, and anti-poly ADP ribose polymerase (PARP) antibodies were obtained from Santa Cruz Biotechnology (Santa Cruz, CA, USA). Anti-nestin, and anti-glial fibrillary acidic protein (GFAP) were purchased from Millipore (Billerica, MA, USA) and MAP1LC3 (LC3) was purchased from Abgent (San Diego, CA, USA). Antibodies against mTOR, p53, cleaved-caspase 3, cleaved-caspase 7, and cleaved-PARP were purchased from Cell Signaling Technology (Beverly, MA, USA), and Akt1 and glyceraldehyde 3-phosphate dehydrogenase (GAPDH) were purchased from AbFrontier (Seoul, Korea).

\section{Cell culture and $\mathrm{MeHg}$ treatment}

HB1.F3 (F3) human NSCs have been described previously (Cho et al., 2002). F3 cells were grown in Dulbecco's modified Eagle's medium (DMEM) with high glucose $(4,500 \mathrm{mg} / \mathrm{l})$ containing $10 \%$ fetal bovine serum (FBS), 100 units/ml penicillin $\mathrm{G}$ sodium and
$100 \mu \mathrm{g} / \mathrm{ml}$ streptomycin sulfate (GibcoBRL, Grand Island, NY, USA) in a humidified incubator in an atmosphere of $5 \% \mathrm{CO}_{2}$ at $37^{\circ} \mathrm{C}$ and subsequently cultured with or without $\mathrm{MeHg}$. Dimethyl sulphoxide (DMSO) was used as a vehicle control.

\section{Cell viability}

Cell proliferation was measured using a Cell Counting Kit-8 (CCK-8; Dojindo, Kumamoto, Japan). Briefly, $5 \times 10^{3}$ cells were placed into well of a 96-well plate and incubated with or without $\mathrm{MeHg}$ for $48 \mathrm{hr}$. After incubation, $10 \mu \mathrm{l}$ of CCK-8 solution was added to each well to a final volume of $100 \mu \mathrm{l}$ of culture medium containing viable cells and an additional incubation for $1 \mathrm{hr}$. Spectrophotometric absorbance at $450 \mathrm{~nm}$ was measured using a Bio-Rad Model 680 microplate reader (Bio-Rad).

\section{Microscopy and photography}

Cells were examined using a CK2 inverted microscope (Olympus, Tokyo, Japan) equipped with a model PC1015 digital camera (Canon, Tokyo, Japan).

\section{Transmission electron microscopy (TEM)}

F3 cells were fixed with a solution of $2.5 \%$ glutaraldehyde with $1 \%$ osmium tetroxide (OsO4) buffer for $2 \mathrm{hr}$ at $4{ }^{\circ} \mathrm{C}$ and dehydrated with ethanol at $4{ }^{\circ} \mathrm{C}$. Then, cells were infiltrated in a 1:1 mixture of propylene oxide and Epon, and finally embedded in Epon by polymerization at $70^{\circ} \mathrm{C}$ for $24 \mathrm{hr}$. Ultrathin sections $(40-70 \mathrm{~nm})$ were cut and mounted on pioloform-coated copper grids. Sections were stained with lead citrate and uranyl acetate and viewed with a JEM 1010 transmission electron microscope (JEOL, Tokyo, Japan).

\section{Western blot analysis}

F3 cells were cultured with or without $\mathrm{MeHg}$ for 48 hr. Cells were lysed using Cell Culture Lysis 5 X Reagent (Promega, Madison, WI, USA) containing Xpert protease inhibitor cocktail solution (GenDEPOT, Barker, TX, USA), and transferred supernatant to a new tube after centrifugation at $10,000 \times \mathrm{g}$ for $15 \mathrm{~min}$ at $4^{\circ} \mathrm{C}$. After measuring the protein concentration of the lysates using a Bradford Protein Assay Kit (Bio-Rad, Hercules, CA, USA), $25 \mu \mathrm{g}$ of protein were separated by $10-15 \%$ sodium dodecyl sulfate-polyacrylamide gel electrophoresis (SDSPAGE) and transferred to nitrocellulose membranes. Membranes were blocked with Tris-buffered Saline containing tween-20 (TTBS) containing 5\% skim milk for $1 \mathrm{hr}$ at room temperature and immunoblotting was performed by incubation overnight at $4{ }^{\circ} \mathrm{C}$ with the corresponding primary antibodies in 5\% skim milk and then 
$\mathrm{MeHg}$ induced apoptosis and autophagy in human NSCs

with secondary antibodies conjugated to horseradish peroxidase for $1 \mathrm{hr}$ at room temperature. After washing, the bands of interest were visualized using a model LAS-3000 luminescent image analyzer (Fujifilm, Tokyo, Japan). Quantification of Western blot analysis was conducted using the Multi Gauge version 3.0 program (Fujifilm).

\section{4', 6-Diamidino-2-phenylindole (DAPI) staining and immunostaining}

F3 cells $\left(1 \times 10^{4}\right)$ were seeded in eight-well chamber slides (BD BioCoat Poly-D-Lysin/Laminin; BD, Franklin Lakes, NJ, USA) and subsequently cultured with or without $\mathrm{MeHg}$ for $48 \mathrm{hr}$. Slides were washed with phosphate buffered saline (PBS) and fixed in $4 \%$ paraformaldehyde (PFA) for $10 \mathrm{~min}$ at $37^{\circ} \mathrm{C}$. Slides were washed and fixed again with methanol and acetone in a volume ratio of $1: 1$. After being blocked with $3 \%$ bovine serum albumin (BSA) in TTBS for $1 \mathrm{hr}$, cells were incubated with a 1:200-1:500 dilution of primary antibody overnight at $4{ }^{\circ} \mathrm{C}$, washed, and incubated with a 1:200 dilution of Alexa Fluor 488-conjugated secondary antibody for $2 \mathrm{hr}$ at room temperature. After washing, coverslips were mounted using FLUOROSHIELD ${ }^{\mathrm{TM}}$ mounting medium with DAPI (ImmunoBioScience, Mukilteo, WA, USA). The slides were visualized using a fluorescent microscope (Carl Zeiss, Jena, Germany).

\section{Flow cytometry analysis}

F3 cells $\left(1 \times 10^{6}\right)$ were seeded in T25 flask and subsequently cultured without or with $\mathrm{MeHg}(1 \mu \mathrm{M})$. Fortyeight hours after $\mathrm{MeHg}$ treatment, cells were processed with an EzWay ${ }^{\mathrm{TM}}$ Annexin V-fluorescein isothiocynate (FITC) Apoptosis Detection kit (KomaBiotec, Seoul, Korea) according to the manufacturer's instructions. Trypsinized cells $\left(5 \times 10^{5}\right)$ were washed with $0.5 \mathrm{ml}$ cold PBS, and remove PBS by centrifugation at $1,000 \times \mathrm{g}$ for $5 \mathrm{~min}$ at room temperature (RT). Washed cells were suspended with $0.5 \mathrm{ml}$ cold $1 \times$ Binding buffer, and added $1.25 \mu \mathrm{l}$ of Annexin V-FITC and incubated for $15 \mathrm{~min}$ at RT in the dark. After removed the supernatant by centrifugation at $1,000 \times \mathrm{g}$ for $5 \mathrm{~min}$ at RT, cells were washed with $0.5 \mathrm{ml}$ cold $1 \times$ Binding buffer and added $10 \mu \mathrm{PI}$. The stained cells $\left(1 \times 10^{4}\right)$ with Annexin V-FITC and PI were analyzed by fluorescence-activated cell sorting (FACS) using a FACSCalibur apparatus (BD Bioscience, San Jose, CA, USA).

\section{RESULTS}

\section{Effects of MeHg on human NSC proliferation and morphology}

Human NSCs were treated with different concentrations $(0.01,0.05,0.1,0.5$ and $1 \mu \mathrm{M})$ of $\mathrm{MeHg}$ for $48 \mathrm{hr}$ and the effect of $\mathrm{MeHg}$ on cell viability was measured. $\mathrm{MeHg}$ reduced viable cells in a dose-dependent manner. After $48 \mathrm{hr}$, treatment of cells with $1 \mu \mathrm{M} \mathrm{MeHg}$ resulted in about $82 \%$ decrease in cell viability. However, at concentrations below $0.5 \mu \mathrm{M}, \mathrm{MeHg}$ only marginally decreased cell viability compared to non-treated control cells (Fig. 1).

To determine the effect of $\mathrm{MeHg}$ on morphology of human NSCs, images of cells were taken by a digital camera at $100 \times$ magnification. As shown in Fig. 2A, cell shrinkage was evident in MeHg-treated cells compared with control or vehicle (DMSO)-treated cells. Because actin is involved in apoptotic cell death and cell shrinkage (Kayalar et al., 1996; Pedersen et al., 1999), the effect of $\mathrm{MeHg}$ on actin filaments in F3 cells was assessed by Western blot and immunofluorescence analyses. MeHg changed the pattern of actin filaments in F3 cells. However, the quantity of total actin remained unchanged (Figs. $2 \mathrm{~B}$ and $2 \mathrm{C}$ ). To determine whether neuronal differentiation of these cells by $\mathrm{MeHg}$ was affected, Western blot analysis of the stem cell marker Nestin was performed. The result showed that the level of Nestin remained unchanged in the cells following MeHg treatment (Fig. 2B).

\section{Effect of MeHg on apoptosis in human NSCs}

To determine the effect of $\mathrm{MeHg}$ on apoptosis and

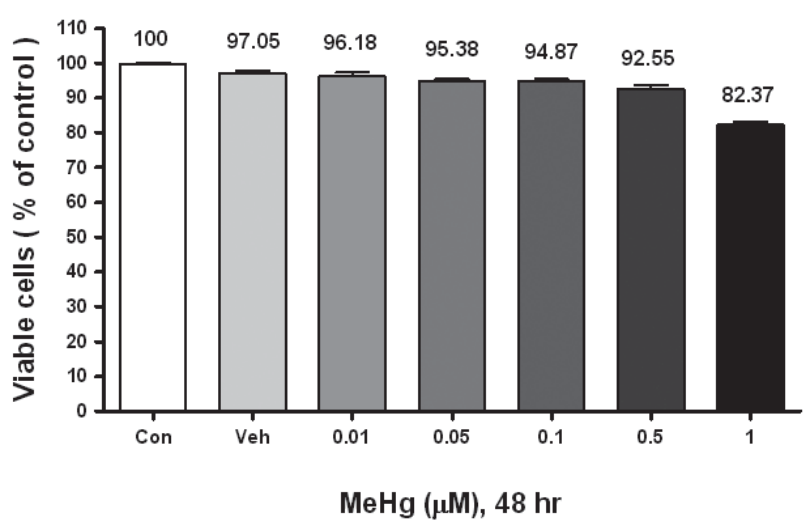

Fig. 1. Effects of MeHg on cell viability of F3 human NSCs. F3 cells $\left(5 \times 10^{3}\right.$ cells/well $)$ were treated with various concentrations $(0-1 \mu \mathrm{M})$ of $\mathrm{MeHg}$ for $48 \mathrm{hr}$. Cell viability was measured using a CCK-8 $(n=10)$. Values are the means \pm S.E.M. 

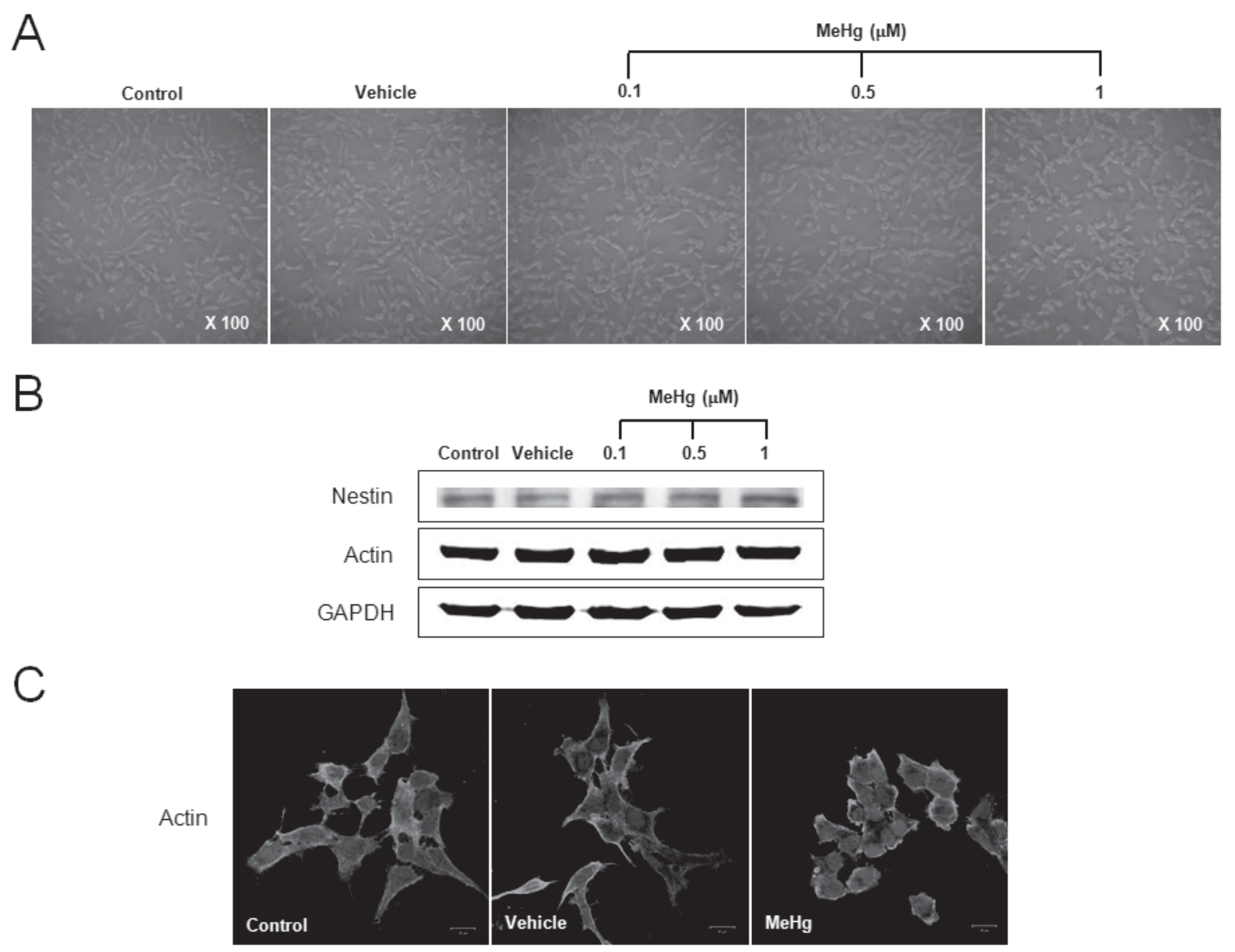

Fig. 2. Effects of MeHg on cell morphology of F3 human NSCs. (A) Morphological change of cells after treatment with MeHg. F3 cells were treated with various concentrations $(0.1,0.5$ and $1 \mu \mathrm{M})$ of $\mathrm{MeHg}$ for $48 \mathrm{hr}$, and observed under $100 \times$ magnification. (B) Western blot analysis of Nestin and Actin. Cells were treated with $\mathrm{MeHg}(0.1,0.5$ and $1 \mu \mathrm{M})$ for $48 \mathrm{hr}$ and harvested, then cell lysates were subjected to Western blot analysis. Blots were probed with antibodies as indicated. (C) Immunofluorescence assay of Actin in F3 cells treated with MeHg. Cells were incubated for $48 \mathrm{hr}$, followed by fixing and immunostaining for Actin (green via Alexa Fluor 488) and nuclei (blue via DAPI). The scale bar represents $20 \mu \mathrm{m}$.

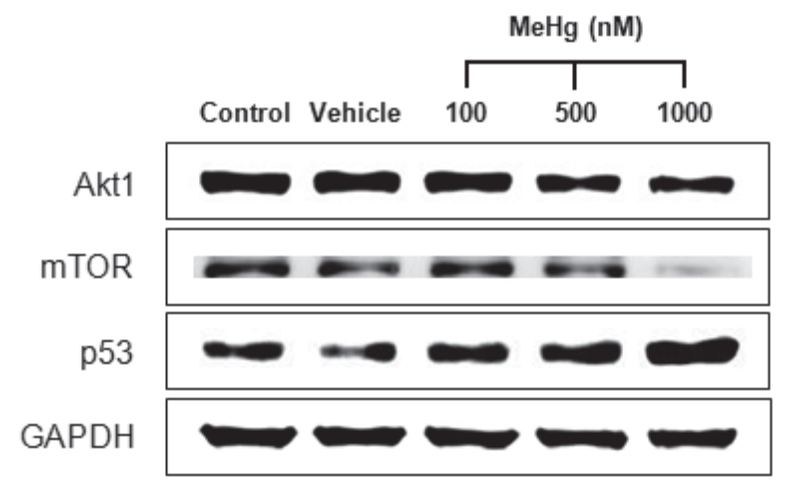

Fig. 3. Dose-dependent effects of MeHg on Akt1/mTOR expression. Western blot analysis of Akt1, mTOR, and p53. F3 cells were treated with various concentrations $(0.1,0.5$ and $1 \mu \mathrm{M})$ of $\mathrm{MeHg}$ for $48 \mathrm{hr}$, and cell lysates were subjected to Western blot analysis. Blots were probed with antibodies as indicated. autophagy in F3 NSCs, Western blot analysis for Akt1/ mTOR, the upstream signal of apoptosis or autophagy, was performed. A dose-dependent decrease in Akt1 and mTOR expression levels was evident. In contrast p53 expression in MeHg-treated cells was increased (Fig. 3). Because p53 has a crucial role in cell cycle arrest and induction of apoptosis, the expression levels of apoptosis related proteins were investigated in $\mathrm{MeHg}$-treated or control F3 cells. The expression levels of proteins involved in caspase-dependent apoptosis (c-caspase 3 and c-caspase 7) were increased by $\mathrm{MeHg}$. As well, an increase in c-PARP protein level was evident in cells treated with $\mathrm{MeHg}$ (Fig. 4A). To confirm the induction of caspasedependent apoptosis by $\mathrm{MeHg}$, inhibitor assay was performed and apoptosis was clearly reduced (Fig. 4B). To further confirm the MeHg-mediated induction of apopto- 
$\mathrm{MeHg}$ induced apoptosis and autophagy in human NSCs

A

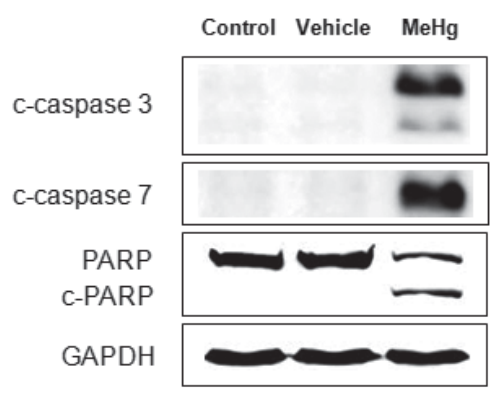

C

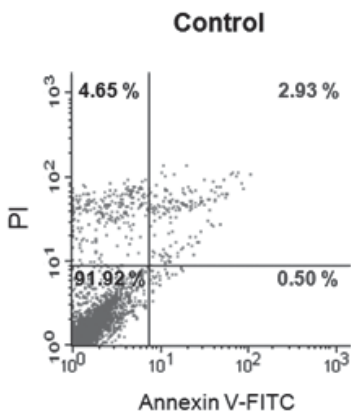

Annexin V-FITC

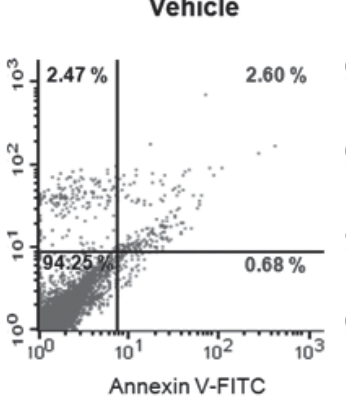

Annexin V-FITC

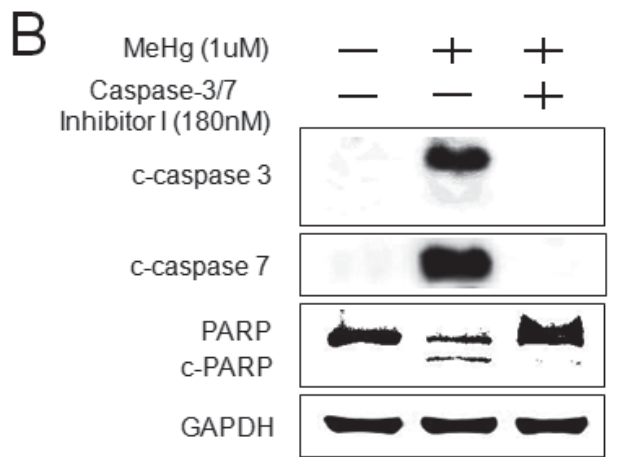

$\mathrm{D}$

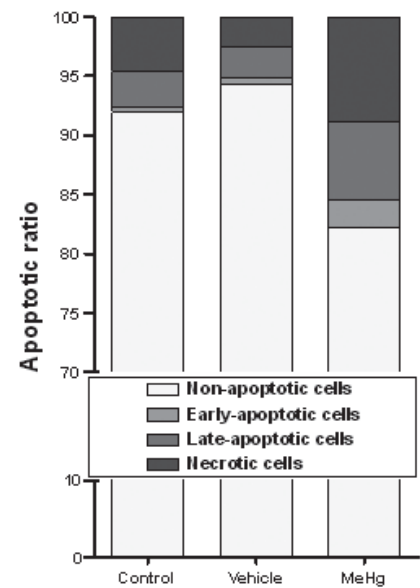

Fig. 4. Effects of MeHg on apoptosis of F3 human NSCs. (A) Western blot analysis of apoptosis-related proteins. F3 cells were treated with $1 \mu \mathrm{M} \mathrm{MeHg}$ for $48 \mathrm{hr}$, and cell lysates were subjected to Western blot analysis. Blots were probed with antibodies as indicated. (B) Inhibition of caspase-dependent apoptosis by caspase-3/7 inhibitor. F3 cells were pretreated with caspase-3/7 inhibitor I (180 nM) for $4 \mathrm{hr}$, and treated with $1 \mu \mathrm{M} \mathrm{MeHg}$ for $48 \mathrm{hr}$, and then cell lysates were subjected to Western blot analysis. Blots were probed with antibodies as indicated. (C) Annexin V-FITC staining after MeHg treatment. F3 cells were treated with $1 \mu \mathrm{M} \mathrm{MeHg}$ and cultures for $48 \mathrm{hr}$, and each group of cells stained with Annexin V-FITC and PI, then analyzed by flow cytometry. (D) Diagram of Annexin V-FITC staining. It represents the percentage of apoptosis of F3 cells.

sis, FACS analysis was performed. In F3 cells treated with $\mathrm{MeHg}$, early apoptosis (Annexin V-positive and PI-negative) (Fig. 4C; lower right) and late apoptosis (Annexin V-positive and PI-positive) (Fig. 4C; upper right) were clearly increased compared with control or vehicle-treated cells (Fig. 4C). Fig. 4D is a diagram which represents the percentage of apoptosis of F3 cells. MeHg-treated cells have increased compared to non-treated group.

\section{Effect of MeHg on autophagy in HB1.F3 human NSCs}

To investigate the effect of $\mathrm{MeHg}$ on autophagy, Western blot analysis was carried out in F3 cells. $\mathrm{MeHg}$ increased the protein level of BECN1 and the ratio of
LC3-II to LC3-I at $48 \mathrm{hr}$ (Fig. 5A). The increase in LC3II protein level was further confirmed by immunofluorescence analysis. The number of LC3 dots was clearly increased in MeHg-treated cells (Fig. 5B). Furthermore, the effect of $\mathrm{MeHg}$ on autophagy was detected by transmission electron microscopy. Large numbers of autophagic vesicles (AVs) were found in MeHg-treated cells compared with control and vehicle-treated cells (Fig. 5C).

\section{Effect of MeHg on neural differentiation in human NSCs}

To induce the neural phenotype, F3 cells were cultured with RA in the presence or absence of $\mathrm{MeHg}$ for $48 \mathrm{hr}$. A morphological change was observed when cells treat- 
S.-H. Chang et al.
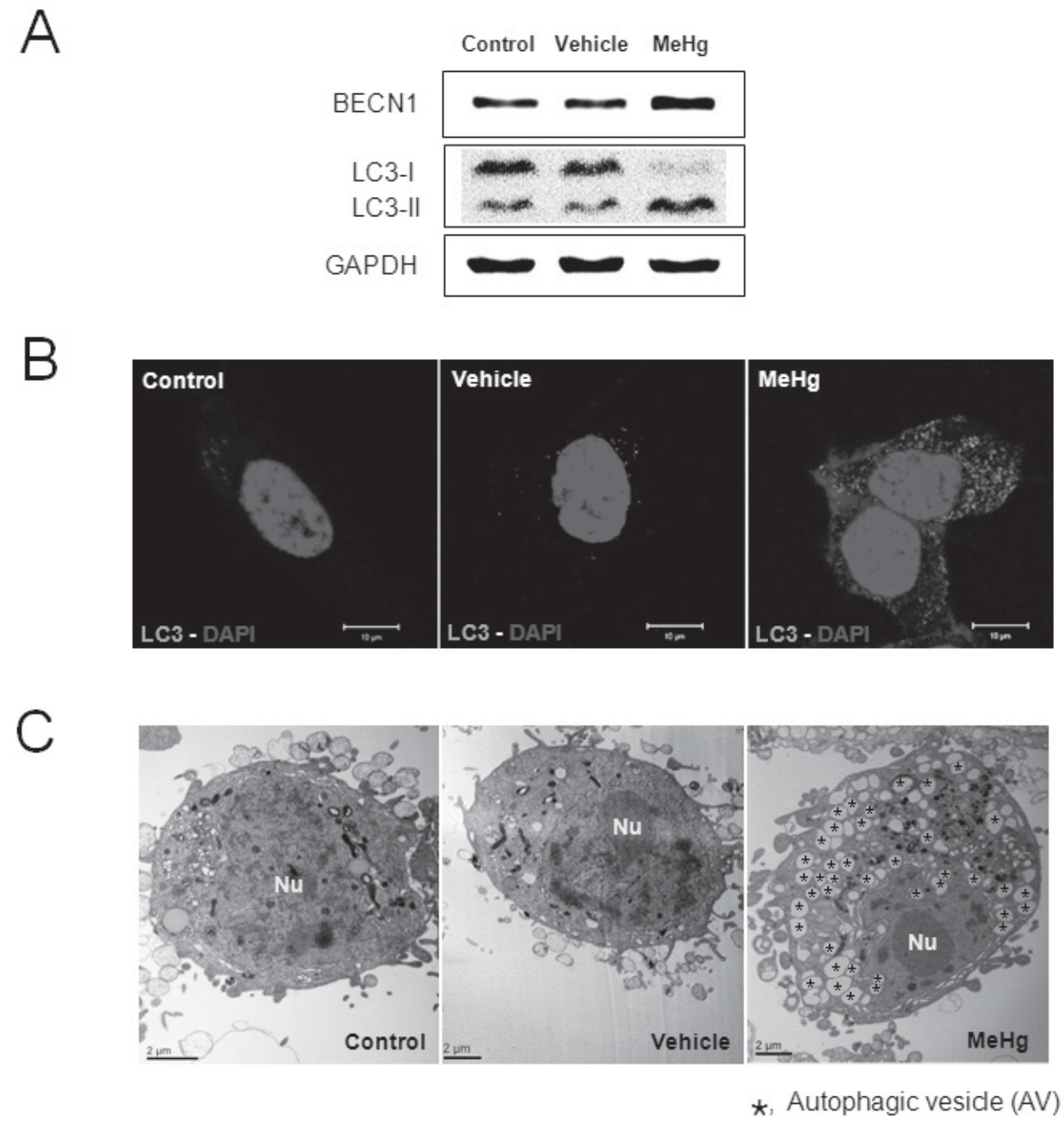

Fig. 5. Effects of MeHg on autophagy of F3 human NSCs. (A) Western blot analysis of BECN1 and LC3. F3 cells were treated with $1 \mu \mathrm{M} \mathrm{MeHg}$ for $48 \mathrm{hr}$, and cell lysates were subjected to Western blot analysis. Blots were probed with antibody of BECN1 or LC3. (B) Immunofluorescence of LC3 in MeHg-treated, vehicle-treated or control F3 cells. Cells were treated with $1 \mu \mathrm{M} \mathrm{MeHg}$ for $48 \mathrm{hr}$, followed by fixing and immunostaining for LC3 (green via Alexa Fluor 488) and nuclei (blue via DAPI). The scale bar represents $10 \mu \mathrm{m}$. (C) TEM analysis of MeHg-treated cells. F3 cells were treated with $1 \mu \mathrm{M}$ $\mathrm{MeHg}$ for $48 \mathrm{hr}$, fixed and analyzed via TEM. The scale bars represents $2 \mu \mathrm{m}$. Nu denotes nucleus and * denotes autophagic vesicle.

ed with RA (Fig. 6A). To confirm the neuronal differentiation of these cells, Western blot analyses of the stem cell marker Nestin and the neural marker GFAP were performed after treatment of cells with MeHg. Differentiated cells induced by RA showed decreased expression level of Nestin compared with undifferentiated cells whereas, decreasaed expression level of Nestin was not observed in differentiated cells treated with $\mathrm{MeHg}$. The opposite pattern was observed for GFAP expression. The expression level of GFAP in differentiated cells induced by RA was increased compared with undifferentiated cells. However, $\mathrm{MeHg}$-treated cells did not show such pattern of change compared to differentiated cells (Fig. 6B).

\section{DISCUSSION}

$\mathrm{MeHg}$ is a potent neurotoxicant that affects both the developing and mature central nervous system (Costa et al., 2004; Atchison, 2005; Johansson et al., 2007; do Nascimento et al., 2008; Grandjean and Herz, 2011). 
MeHg induced apoptosis and autophagy in human NSCs
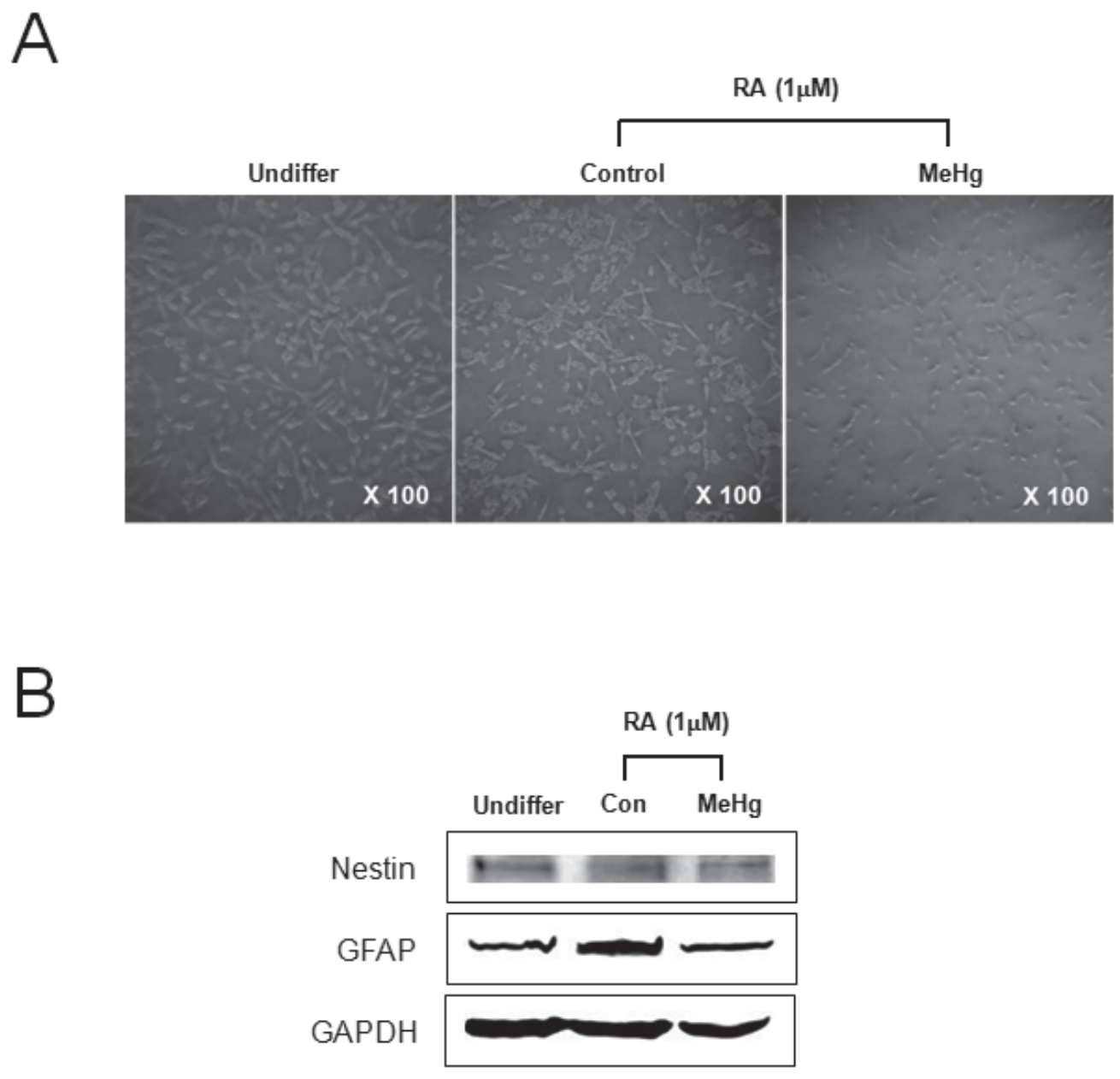

Fig. 6. Effects of MeHg on differentiation of F3 human NSCs. (A) Morphological change of cells after differentiation. F3 cells were treated with $1 \mu \mathrm{M}$ RA in the presence or absence of $1 \mu \mathrm{M} \mathrm{MeHg}$ and observed under $100 \times$ magnification. (B) Western blot analysis of Nestin and GFAP. F3 cells were treated with $1 \mu \mathrm{M} \mathrm{MeHg}$ for $48 \mathrm{hr}$, harvested, and the cell lysates were subjected to Western blot analysis. Blots were probed with antibody to Nestin or GFAP.

MeHg causes widespread and diffuse damage in infants, whereas in the adult brain $\mathrm{MeHg}$ causes focal damage. Exposure to $\mathrm{MeHg}$ is more dangerous to the fetus. Fetuses exposed in utero can be affected in the absence of maternal toxicity (Matsumoto et al., 1965; Choi et al., 1978; Takeuchi, 1982). Damage pattern of MeHg depends on the stage of development when the exposure occurs, as well as duration and concentration (Rodier, 1995). In the present study, we used human NSCs as a model system of fetal CNS to investigate neurotoxic effects of $\mathrm{MeHg}$ and mechanisms underlying these effects.

Exposure to $\mathrm{MeHg}$ can cause necrotic or apoptotic cell death in CNS neurons. Apoptotic cell death is triggered by receptor-mediated or mitochondria-mediated signaling pathways that induce death-associated proteolytic and/ or nucleolytic activities (Orrenius et al., 2003). $\mathrm{MeHg}$ elicits mitochondrial-dependent apoptosis in developing rat hippocampal neurons and C17.2 mouse NSC line (Tamm et al., 2006; Sokolowski et al., 2011). However, several alternative cell death pathways including caspase-independent programmed cell death (PCD), necrosis-like PCD, and mitotic or autophagic cell death are present (Leist and Jäättelä, 2001; Jäättelä, 2002; Edinger and Thompson, 2004; Gozuacik and Kimchi, 2004; Levine and Yuan, 2005). Autophagy constitutes a stress adaptation that avoids cell death during nutrient starvation and which suppresses apoptosis (Maiuri et al., 2007), or constitutes an alternative cell-death pathway (Edinger and 
Thompson, 2004; Gozuacik and Kimchi, 2004). Autophagy and apoptosis are triggered by common upstream signals, sometimes resulting in combined autophagy and apoptosis, whereas cells switch between the two responses in a mutually exclusive manner (Baehrecke, 2005; Kroemer and Jäättelä, 2005). In a previous study, we demonstrated significantly increased autophagy in A549 lung cancer cells having stably elevated $B E C N 1$ expression, while decreased levels of apoptosis-related proteins such as Bax and cleaved PARP were observed (Chang et al., 2012). In the present study, we also examined the effect of $\mathrm{MeHg}$ on apoptosis and autophagy. Our results clearly showed induction of caspase-dependent apoptosis and autophagy in MeHg-treated human NSCs.

Differentiated cells have morphological features that correlate with their specialized functions in organs. These special features include membrane protrusions such as bristles, microvilli, stereocilia, filopodia, and lamellipodia, which are formed and maintained by the underlying actin cytoskeleton (Revenu et al., 2004). Microvilli and microvilli-like structures are observed in a variety of polarized cells. Cell polarity is observed in most differentiated cells, even prokaryotes. Although observed in different forms in diverse cell types and species, polarity is defined by two fundamental properties, the asymmetric accumulation of mobile components between opposite poles of a cell and the orientated organization of inherently polar cytoskeletal filaments (particularly actin and microtubules) along the axis of polarity ( $\mathrm{Li}$ and Gundersen, 2008). Neurons are highly polarized cells that might stimulate axon formation by localized actin instability (Bradke and Dotti, 1999). Studies of embryonic rodent hippocampal neurons have provided information on the factors involved in specifying neuronal cell polarity (Wiggin et al., 2005; Arimura and Kaibuchi, 2007). Hippocampal neurons initially extend multiple morphologically indistinguishable and undifferentiated neurites. Symmetry of cytoskeletal filaments is broken when one of the neurites begins to grow rapidly and acquires axonal markers, such as dephosphorylated tau and microtubule-associated protein (MAP), whereas the other neurites remain unchanged. Over time, the short neurites begin to grow and differentiate into dendrites by acquiring dendritic markers such as MAP2 (Kosik and Finch, 1987). Our results suggest that structural change observed in actin filaments may result in inhibition of morphology and cellular differentiation.

In conclusion, $\mathrm{MeHg}$ inhibits the differentiation of F3 human NSCs through induction of caspase-dependent apoptosis and autophagy.

\section{ACKNOWLEDGMENTS}

Part of this work is supported by the National Research Foundation of Korea (NRF) funded by the Ministry of Science, ICT \& Future Planning (2012M3A9C4048819). M.H. Cho was also partially supported by the Research Institute for Veterinary Science, Seoul National University.

\section{REFERENCES}

Arico, S., Petiot, A., Bauvy, C., Dubbelhuis, P.F., Meijer, A.J., Codogno, P. and Ogier-Denis, E. (2001): The tumor suppressor PTEN positively regulates macroautophagy by inhibiting the phosphatidylinositol 3-kinase/protein kinase B pathway. J. Biol. Chem., 276, 35243-35246.

Arimura, N. and Kaibuchi, K. (2007): Neuronal polarity: from extracellular signals to intracellular mechanisms. Nature Rev. Neurosci., 8, 194-205.

Atchison, W.D. (2005): Is chemical neurotransmission altered specifically during methylmercury-induced cerebellar dysfunction? Trends Pharmacol. Sci., 26, 549-557.

Baehrecke, E.H. (2002): How death shapes life during development. Nat. Rev. Mol. Cell. Biol., 3, 779-787.

Baehrecke, E.H. (2005): Autophagy: dual roles in life and death? Nat. Rev. Mol. Cell. Biol., 6, 505-510.

Berry, D.L. and Baehrecke, E.H. (2007): Growth arrest and autophagy are required for salivary gland cell degradation in Drosophila. Cell, 131, 1137-1148.

Bradke, F. and Dotti, C.G. (1999): The role of local actin instability in axon formation. Science, 283, 1931-1934.

Castoldi, A.F., Barni, S., Turin, I., Gandini, C. and Manzo, L. (2000): Early acute necrosis, delayed apoptosis and cytoskeletal breakdown in cultured cerebellar granule neurons exposed to methylmercury. J. Neurosci. Res., 59, 775-787.

Chang, S.H., Hong, S.H., Jiang, H.L., Minai-Tehrani, A., Yu, K.N., Lee, J.H., Kim, J.E., Shin, J.Y., Kang, B., Park, S., Han, K., Chae, C. and Cho, M.H. (2012): GOLGA2/GM130, cis-Golgi matrix protein, is a novel target of anticancer gene therapy. Mol. Ther., 20, 2052-2063.

Chang, S.H., Minai-Tehrani, A., Shin, J.Y., Park, S., Kim, J.E., Yu, K.N., Hong, S.H., Hong, C.M., Lee, K.H., Beck, GR.Jr. and Cho, M.H. (2012): Beclin1-induced autophagy abrogates radioresistance of lung cancer cells by suppressing osteopontin. J. Radiat. Res., 53, 422-432.

Cho, T., Bae, J.H., Choi, H.B., Choi, H.B., Kim, S.S., McLarnon, J.G., Suh-Kim, H., Kim, S.U. and Min, C.K. (2002): Human neural stem cells: electrophysiological properties of voltage-gated ion channels. Neuroreport, 13, 1447-1452.

Choi, B.H., Lapham, L.W., Amin-Zaki, L. and Saleem, T. (1978): Abnormal neuronal migration, deranged cerebral cortical organization, and diffuse white matter astrocytosis of human fetal brain: a major effect of methylmercury poisoning in utero. J. Neuropathol. Exp. Neurol., 37, 719-733.

Clarkson, T.W., Magos, L. and Myers, G.J. (2003): The toxicology of mercury-current exposures and clinical manifestations. N. Engl. J. Med., 349, 1731-1737.

Costa, L.G., Aschner, M., Viltalone, A., Syversen, T. and Soldin, O.P. (2004): Developmental neuropathology of environmental 
$\mathrm{MeHg}$ induced apoptosis and autophagy in human NSCs

agents. Annu. Rev. Pharmacol. Toxicol., 44, 87-110.

Daré, E., Götz, M.E., Zhivotovsky, B., Manzo, L. and Ceccatelli, S. (2000): Antioxidants J811 and 17beta-estradiol protect cerebellar granule cells from methylmercury-induced apoptotic cell death. J. Neurosci. Res., 62, 557-565.

do Nascimento, J.L.M., Oliveira, K.R., Crespo-Lopez, M.E., Macchi, B.M., Maués, L.A., Pinheiro, Mda C., Silveira, L.C. and Herculano, A.M. (2008): Methylmercury neurotoxicity \& antioxidant defenses. Indian J. Med. Res., 128, 373-382.

Edinger, A.L. and Thompson, C.B. (2004): Death by design: apoptosis, necrosis and autophagy. Curr. Opin. Cell Biol., 16, 663669.

Farina, M., Aschner, M. and Rocha, J.B.T. (2011): Oxidative stress in MeHg-induced neurotoxicity. Toxicol. Appl. Pharmacol., 256, 405-417.

Furuta, S., Hidaka, E., Ogata, A., Yokota, S. and Kamata, T. (2004): Ras is involved in the negative control of autophagy through the class I PI3-kinase. Oncogene, 23, 3898-3904.

Gozuacik, D. and Kimchi, A. (2004): Autophagy as a cell death and tumor suppressor mechanism. Oncogene, 23, 2891-2906.

Grandjean, P. and Herz, K.T. (2011): Methylmercury and brain development: imprecision and underestimation of developmental neurotoxicity in humans. Mt Sinai J. Med., 78, 107-118.

Hassan, S.A., Moussa, E.A. and Abbott, L.C. (2012): The effect of methylmercury exposure on early central nervous system development in the zebrafish (Danio rerio) embryo. J. Appl. Toxicol., 32, 707-713.

Jäättelä, M. (2002): Programmed cell death: many ways for cells to die decently. Ann. Med., 34, 480-488.

Johansson, C., Castoldi, A.F., Onishchenko, N., Manzo, L., Vahter, M. and Ceccatelli, S. (2007): Neurobehavioural and molecular changes induced by methylmercury exposure during development. Neurotox. Res., 11, 241-260.

Kayalar, C., Ord, T., Testa, M.P., Zhong, L.T. and Bredesen, D.E. (1996): Cleavage of actin by interleukin 1 beta-converting enzyme to reverse DNase I inhibition. Proc. Natl. Acad. Sci. USA, 93, 2234-2238.

Kim, S.H. and Sharma, R.P. (2004): Mercury-induced apoptosis and necrosis in murine macrophages: role of calcium-induced reactive oxygen species and p38 mitogen-activated protein kinase signaling. Toxicol. Appl. Pharmacol., 196, 47-57.

Kondo, Y., Kanzawa, T., Sawaya, R. and Kondo, S. (2005): The role of autophagy in cancer development and response to therapy. Nat. Rev. Cancer, 5, 726-734.

Kosik, S. and Finch, E.A. (1987): MAP2 and tau segregate into dendritic and axonal domains after the elaboration of morphologically distinct neurites: an immunocytochemical study of cultured rat cerebrum. J. Neurosci., 7, 3142-3153.

Kroemer, G. and Jäättelä, M. (2005): Lysosomes and autophagy in cell death control. Nat. Rev. Cancer, 5, 886-897.

Kuma, A., Hatano, M., Matsui, M., Yamamoto, A., Nakaya, H., Yoshimori, T., Ohsumi, Y., Tokuhisa, T. and Mizushima, N. (2004): The role of autophagy during the early neonatal starvation period. Nature, 432, 1032-1036.
Leist, M. and Jäättelä, M. (2001): Four deaths and a funeral: from caspases to alternative mechanisms. Nat. Rev. Mol. Cell Biol., 2, 589-598.

Levine, B. and Yuan, J. (2005): Autophagy in cell death: an innocent convict? J. Clin. Invest., 115, 2679-2688.

Li, R. and Gundersen, G.G. (2008): Beyond polymer polarity: how the cytoskeleton builds a polarized cell. Nat. Rev. Mol. Cell Biol., 9, 860-873.

Lu, T.H., Hsieh, S.Y., Yen, C.C., Wu, H.C., Chen, K.L., Hung, D.Z., Chen, C.H., Wu, C.C., Su, Y.C., Chen, Y.W., Liu, S.H. and Huang, C.F. (2011): Involvement of oxidative stress-mediated ERK1/2 and p38 activation regulated mitochondria-dependent apoptotic signals in methylmercury-induced neuronal cell injury. Toxicol. Lett., 204, 71-80.

Maiuri, M.C., Zalckvar, E., Kimchi, A. and Kroemer, G. (2007): Self-eating and self-killing: crosstalk between autophagy and apoptosis. Nat. Rev. Mol. Cell Biol., 8, 741-752.

Matsumoto, H., Koya, G. and Takeuchi, T. (1965): Fetal Minamata disease. A neuropathological study of two cases of intrauterine intoxication by a methyl mercury compound. J. Neuropathol. Exp. Neurol., 24, 563-574.

Mizushima, N., Ohsumi, Y. and Yoshimori, T. (2002): Autophagosome formation in mammalian cells. Cell Struct. Funct., 27, 421-429.

Orrenius, S., Zhivotovsky, B. and Nicotera, P. (2003): Regulation of cell death: the calcium-apoptosis link. Nat. Rev. Mol. Cell Biol., 4, 552-565.

Pedersen, S.F., Mills, J.W. and Hoffmann, E.K. (1999): Role of the F-actin cytoskeleton in the RVD and RVI processes in Ehrlich ascites tumor cells. Exp. Cell Res., 252, 63-74.

Reggiori, F. and Klionsky, D.J. (2005): Autophagosomes: biogenesis from scratch? Curr. Opin. Cell Biol., 17, 415-422.

Revenu, C., Athman, R., Robine, S. and Louvard, D. (2004): The co-workers of actin filaments: from cell structures to signals. Nat. Rev. Mol. Cell Biol., 5, 635-646.

Rice, D.C., Schoeny, R. and Mahaffey, K. (2003): Methods and rationale for derivation of a reference dose for methylmercury by the U.S. EPA. Risk Anal., 23, 107-115.

Rodier, P.M. (1995): Developing brain as a target of toxicity. Environ. Health Perspect., 103, 73-76.

Sokolowski, K., Falluel-Morel, A., Zhou, X. and DiCicco-Bloom, E. (2011): Methylmercury (MeHg) elicits mitochondrial-dependent apoptosis in developing hippocampus and acts at low exposures. Neurotoxicology, 32, 535-544.

Takeuchi, T. Pathology of Minamata disease. (1982): With special reference to its pathogenesis. Acta Pathol. Jpn., 32, 73-99.

Tamm, C., Duckworth, J., Hermanson, O. and Ceccatelli, S. (2006): High susceptibility of neural stem cells to methylmercury toxicity: effects on cell survival and neuronal differentiation. J. Neurochem., 97, 69-78.

Wiggin, G.R., Fawcett, J.P. and Pawson, T. (2005): Polarity proteins in axon specification and synaptogenesis. Dev. Cell, 8, 803-816. 